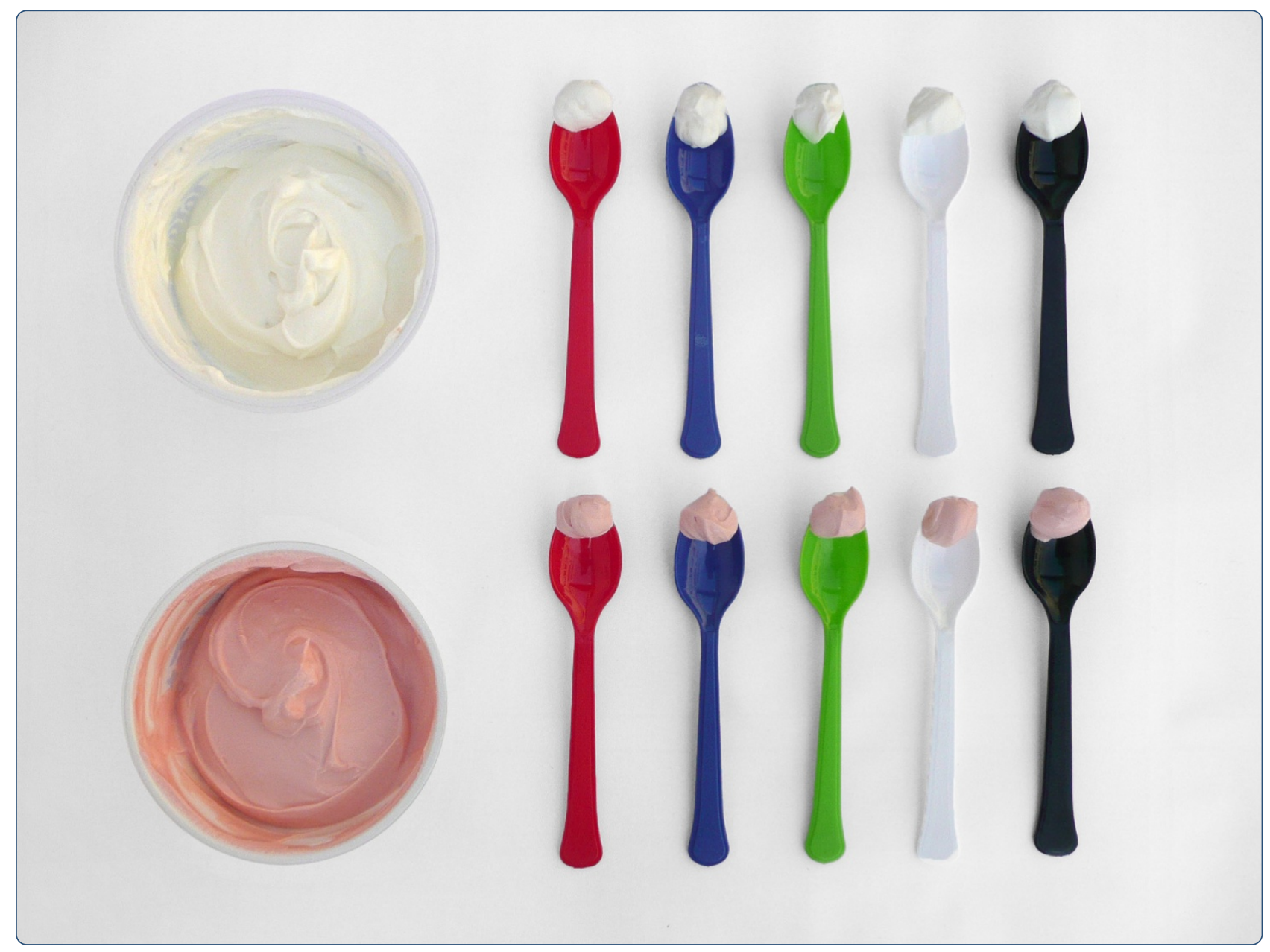

The taste of cutlery: how the taste of food is affected by the weight, size, shape, and colour of the cutlery used to eat it

Harrar and Spence

C Biomed Central 


\title{
The taste of cutlery: how the taste of food is affected by the weight, size, shape, and colour of the cutlery used to eat it
}

\author{
Vanessa Harrar ${ }^{*}$ and Charles Spence
}

\begin{abstract}
Background: Recent evidence has shown that changing the plateware can affect the perceived taste and flavour of food, but very little is known about visual and proprioceptive influences of cutlery on the response of consumers to the food sampled from it. In the present study, we report three experiments designed to investigate whether food tastes different when the visual and tactile properties of the plastic cutlery from which it is sampled are altered. We independently varied the weight, size, colour, and shape of cutlery. We assessed the impact of changing the sensory properties of the cutlery on participants' ratings of the sweetness, saltiness, perceived value, and overall liking of the food tasted from it.

Results: The results revealed that yoghurt was perceived as denser and more expensive when tasted from a lighter plastic spoon as compared to the artificially weighted spoons; the size of the spoon only interacted with the spoon-weight factor for the perceived sweetness of the yoghurt. The taste of the yoghurt was also affected by the colour of the cutlery, but these effects depended on the colour of the food as well, suggesting that colour contrast may have been responsible for the observed effects. Finally, we investigated the influence of the shape of the cutlery. The results showed that the food was rated as being saltiest when sampled from a knife rather than from a spoon, fork, or toothpick.
\end{abstract}

Conclusions: Taken together, these results demonstrate that the properties of the cutlery can indeed affect people's taste perception of everyday foods, most likely when expectations regarding the cutlery or the food have been disconfirmed. We discuss these results in the context of changing environmental cues in order to modify people's eating habits.

Keywords: Flavour, Cutlery, Hedonic rating, Sweetness, Colour, Weight, Multisensory, Expectation, Disconfirmed expectation

\section{Background}

Many of the foods that we enjoy are unhealthy: high in fat, sugar, and salt, and tend to be low in vitamins. Despite rigorous information campaigns aimed at informing people about the risks associated with such consumption habits, we are generally rather poor at changing our (mostly automatic) consumption behaviours [1]. Recently, Marteau and colleagues [2] have suggested that one way in which to change our automatic behaviours toward food products may be to change food product

\footnotetext{
* Correspondence: vanessa.harrar@psy.ox.ac.uk

Crossmodal Research Laboratory, Department of Experimental Psychology, University of Oxford, South Parks Road, Oxford OX1 3UD, United Kingdom
}

design or to somehow alter the environment in which those food products are selected or consumed. While food science and technology has mostly focused on changing the sensory attributes of the food itself, a cognitive neuroscience perspective has also demonstrated the influence that changes to the tableware can have on the taste and flavour of food (see [3] for a review).

Consumption behaviours can change with the shape of the glass $[4,5]$, the size of the plateware [6-8], and the size of the cutlery with which a person eats $[9,10]$. Consumption behaviours are also affected by what a person hears (see [11] for a review) as well as by ambient lighting and music [12-14].

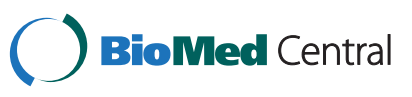

(c) 2013 Harrar and Spence; licensee BioMed Central Ltd. This is an Open Access article distributed under the terms of the Creative Commons Attribution License (http://creativecommons.org/licenses/by/2.0), which permits unrestricted use, distribution, and reproduction in any medium, provided the original work is properly cited. 
The visually estimated size and weight of tools used for eating (hereafter referred to as cutlery) are used to shape the fingers in order to grip the cutlery at a particular location (or affordance point) and with a particular force [15]. Vision and proprioceptive feedback then guide the cutlery, and the food, toward the mouth. As such, the visual as well as tactile and proprioceptive attributes of the cutlery (that is, its colour, size, shape, weight, and texture) are all likely candidates for affecting the multisensory nature of taste and flavour [16]. In the series of experiments to be presented here, the colour, shape, size, and weight of cutlery will be independently altered to verify which of these variables affect flavour perception.

Previous research has demonstrated that the colour of the tableware can affect the flavour of a dish. If a glass has a 'cold' colour, a beverage served from it may well be rated as more thirst-quenching [17-19]. The colour of the plateware can also affect the perceived saltiness and sweetness of the food tasted from it $[20,21]$. The authors of the latter studies suggested that the effect of colour on taste perception most likely reflects an effect of colour-contrast, which, in terms of the current discussion, refers to the colour of food appearing different as a function of the background colour of the plateware and/or cutlery.

The effect of colour (or colour contrast) on flavour perception and consumption behaviour might be mediated by emotion [22,23], especially since thoughts of food and emotions activate similar brain areas [24,25]. As Oberfeld et al. ([12]; p. 807) put it: if a colour induces a positive mood or emotion [...] then the same wine tasted in this positive mood is liked better than when in a negative mood'. Whether the colour is present in the food, the tableware, or in the cutlery itself, it would be expected to have similar effects (though perhaps of a different magnitude) on people's ratings of the taste/flavour of a food or beverage. However, an emotional response to a colour is not the only possible explanation for how colour might affect flavour.

An alternative explanation is that colour affects taste perception because of previous experience which means that people build up expectations associated with certain colours in certain contexts. If the effects of colour on taste are to be explained in terms of expectations, then coloured tableware might be expected to have different effects as compared to coloured food and drink - that is, context matters. If context is important, then red yoghurt might appear as sweeter (making someone think that they are eating strawberry yoghurt) while red plates might make food taste saltier, for example, if the person has had lots of prior experience of eating sushi from a red plate. Expectations may build up as a result of sensory experience, or, as Maga [26] has argued, there might be natural associations between colours and tastes that have been learned over the course of evolution (rather than in our own lifetime). Thus, redness may carry with it an expectation of a fruit being ripe and sweet $([27,28]$ for a review of how sensory expectations affects hedonic ratings see [29]) and indeed colour signals the nutrient quality of fruits [30]. Coloured cutlery has probably not been experienced with any regularity, and thus may carry less flavour expectation than coloured food. In Experiment 2, we compared taste when samples were eaten off of coloured cutlery versus when the samples themselves were coloured with food dye. In addition to expectation and emotion moderating the effect that colour has on flavour perception, an alternative interpretation is that sensation transference (for example, [31]) could cause the sensation of colour in the tableware to be 'transferred' to the food, which might then induce specific sensory expectations in a person's mind.

Sensation transference has been suggested as the likely explanation for how the weight of bowls could affect people's perception of the food consumed from it [32-34]. Participants perceived 'more' of each attribute when holding a heavier porcelain bowl, as compared to a lighter bowl. Piqueras-Fiszman et al. explained that the heaviness of the bowl was 'transferred' to the contents (the food) such that the latter was perceived as thicker and denser (hence more expensive and more liked). Would the results have been the same if a plastic bowl had been artificially weighted instead? Since plastic bowls are expected to be light, expectation theory would predict that food tasted from heavier plastic bowls would be rated as less pleasant than the same food tasted from normally light plastic bowls (due to the disconfirmation of expectation).

In Experiment 1, weights were added to plastic cutlery in order to determine whether the food was, as in Piqueras-Fiszman et al. [35], perceived as more dense/ liked (which would support the sensation transference hypothesis) or less dense/liked (supporting the expectation theory). Weights were hidden in the handles of the cutlery so that, upon visual inspection, the spoons were expected to be light. Other than the weight, all other aspects of the spoon were the same (that is, they did not vary in material, which is is important given the results of [36]). Note that this aspect of the design represents an improvement over previous experiments [33]. We also compared an elaborate, rather expensive, plastic spoon that looked like silverware, to the otherwise simple and cheap plastic spoons. The elaborate spoon, if it were to be mistaken for a 'real' spoon might then be expected to be heavier than it actually was. The elaborate spoon might also appear to be more expensive, and that expense might, in turn, be expected to be 'transferred' onto the perceived value or other attributes of the food sampled from it. Yoghurt was 
thus sampled from four different spoons, two large and two small, two of which were artificially weighted, and participants rated the perceived density, expensiveness, and sweetness of the yoghurt and gave the yoghurt an overall hedonic rating.

In Experiment 2, the colour of the cutlery was varied as well as the colour of the food. Spoons were red, blue, green, white, or black; and the yoghurt sampled from the spoons was either naturally white or else artificially coloured pink. This design enabled us to compare wellknown effects of food colouring, with as yet unknown effects of coloured cutlery. If the colour of the food affects the perceived taste by affecting the consumer's mood and/or emotional state, then a given colour would always be expected to exert a similar effect on the consumer. Comparing the results of this experiment with the results of previous research where coloured bowls were used [20] allowed us to assess the extent to which the effects of colour in tableware are stable across environmental changes.

In Experiment 3, we assessed what effects, if any, the shape of the cutlery might exert on people's taste perception. Food ratings were compared after participants sampled two kinds of cheese (a young cheddar and a mature/aged cheddar) from four types of cutlery (a fork, a spoon, a knife, or a toothpick - thereby varying both the visual and the oral-somatosensory attributes of the cutlery). Would the cheese be perceived as 'sharper' when tasted from a sharp tool? In an as yet unpublished study, Gal et al. [37] describe how cheddar cheese was reported as sharper when sampled after viewing pointy figures as compared to those who sampled the cheese after viewing rounded images. Gal et al. also reported that the influence of geometric figures on the perception of cheese was mediated by participants' overall liking for cheese (and thus their prior experience with cheese).

Expectations and experience with eating certain foods from certain pieces of cutlery might mediate the effects of cutlery shape on taste perception. As cheese is often served with toothpicks at cocktail parties, or from a knife in a cheese shop, we wondered whether eating cheese with the aid of these tools would make the cheese appear more expensive or more liked. Following on from Gal et al.'s [37] research, the participants in Experiment 3 represented two groups of the population: those familiar with the description of cheese as 'sharp' and those who were unfamiliar with such a description. Familiarity with this term can then be taken as a rough measure of the level of experience with cheese, or of verbal descriptions of cheese).

We present results from three experiments that independently varied different properties of the cutlery. As the participants in all studies were from the same participant pool, and the protocol was similar across the studies, we can somewhat directly compare across studies and assess the relative importance of cutlery's weight, size, colour, and shape on consumers responses to the food sampled from it. We measured the perceived sweetness, saltiness, density, sharpness, value, and the overall liking of food sampled from different cutlery, in order to determine which underlying mechanisms (sensation transference, disconfirmation of expectation, or mood/emotion) might be responsible for the effects of tableware on taste perception.

\section{Results and discussion Experiment 1}

The five spoons (two teaspoons, two tablespoons and the 'fancy spoon') were compared to each other using a one-way analysis of variance (ANOVA). The fancy spoon was not significantly different from the others spoons for any of the ratings. Instead, the differences are better captured by comparing the spoon size and spoon weight as independent factors.

The data were analysed with repeated measures ANOVAs performed on the four simple spoons (that is, not including the 'fancy spoon', see above) in order to assess the independent effects of the size and weight of the plastic spoons on participants' taste perception. For each of the four ratings, there were two independent variables (Spoon Size-2 levels X Spoon Weight-2 levels). Table 1 highlights the mean ratings for the yoghurt sampled from each of the spoons. The yoghurt sampled from the heavy teaspoon (weighing nearly three times as much as it would normally) was rated as the least dense, least expensive, and as one of the least liked, but it was also rated as the sweetest. The results demonstrated that the weight of the spoon from which the food was sampled exerted a significant influence on the sensory qualities of the food that was tasted.

Table 1 Means and standard errors of participants' ratings of the yoghurt sampled in experiment 1

\begin{tabular}{lccccc}
\hline & Weight & Density & Expensiveness & Liking & Sweetness \\
\hline Teaspoon & $2.35 \mathrm{~g}$ & $6.05( \pm 0.30)$ & $5.14( \pm 0.25)$ & $5.23( \pm 0.25)$ & $3.00( \pm 0.23)$ \\
Tablespoon & $6.57 \mathrm{~g}$ & $5.43( \pm 0.28)$ & $4.42( \pm 0.27)$ & $4.83( \pm 0.31)$ & $3.71( \pm 0.28)$ \\
& $3.73 \mathrm{~g}$ & $5.77( \pm 0.30)$ & $5.00( \pm 0.30)$ & $4.80( \pm 0.29)$ & $3.66( \pm 0.25)$ \\
Fancy spoon & $10.84 \mathrm{~g}$ & $5.54( \pm 0.28)$ & $4.91( \pm 0.30)$ & $4.94( \pm 0.31)$ & $3.49( \pm 0.25)$ \\
\hline
\end{tabular}


There was a significant effect of Spoon Weight on the perceived density of the yoghurt $\left(\mathrm{F}_{1,34}=4.280, P=.046\right.$, eta $_{\mathrm{p}}^{2}=.112$, see Figure 1a). There was also a significant effect of Spoon Weight on the perceived expensiveness of the yoghurt $\left(\mathrm{F}_{1,34}=4.413, P=.043\right.$, eta $\mathrm{p}_{\mathrm{p}}^{2}=.115$, see Figure 1b). The sampled yoghurt was rated as tasting denser and more expensive when sampled from the lighter spoons, as compared to the visually identical but heavier spoon. This is the opposite pattern of results from [35] who reported that yoghurt was perceived as denser and more expensive when tasted from heavier plateware (see also [38]).

If sensation transference were to constitute the most appropriate explanation for the observed effects, then context should make no difference; heavier plateware should have had the same effect on food perception as heavy cutlery. However, since we report means in the opposite direction, when tested with plastic (usually light) cutlery, we suggest that the effects of tableware weight on taste are mediated by the consumer's expectation of the tableware's weight. That is, when the cutlery or bowl is expected to be light (as here with plastic cutlery) the yoghurt tastes better (more dense and more expensive) when these expectation are met (that is, when the cutlery is light) ${ }^{\mathrm{a}}$.

While spoon size did not affect perceived density and expensiveness of the food, the size of the cutlery appears to be an important factor mediating the effects of cutlery on sweetness - perhaps since some foods (soup or desserts, for instance) are often consumed with cutlery that is of a particular size. The sweetness ratings of the yoghurt were significantly affected by both the spoon's weight and by its size (significant interaction effect $F_{1,34}=5.142$, $P=.030$, eta $_{\mathrm{p}}^{2}=.131$, see Figure $1 \mathrm{c}$ ). When followed up with pairwise comparisons, it turned out that only the lightest spoon (the teaspoon weighing $2.35 \mathrm{~g}$ ) was different from most of the others (heavy teaspoon $t_{34}=2.92$, $P=.006$; light tablespoon: $\mathrm{t}_{34}=2.71, P=.01$; heavy tablespoon $\mathrm{t}_{34}=2.05, P=.048$; but not different from the fancy spoon, $\mathrm{t}_{34}=0.57, P=.57$ ).

Any taste expectations that are based on the size of the spoon might have interacted with any taste expectations based on the spoon's weight, which together appear to have influenced the perceived sweetness of the yoghurt. Small spoons are often used for desserts, or to stir sugar into coffee or tea. There might be an expectation that food tasted from a small spoon would normally be sweeter than food tasted from a larger tablespoon (more often used for savoury dishes such as soups).

It is thus difficult to determine what kind of cutlery would produce the 'best' results; while the yoghurt tasted from the light teaspoon was rated as the most dense, most expensive, and most liked, this spoon would not seem to be the best for eating desserts since the yoghurt tasted from it was rated as the least sweet.

In Experiment 2, we went on to investigate whether taste expectations also provide an explanation for any effects the colour of the cutlery might have on perceived sweetness, saltiness, expensiveness, and the participant's overall liking of yoghurt.

\section{Experiment 2}

T-tests confirmed that the responses obtained during the blind tasting were not significantly different for the pink and the white yoghurt on any of the ratings $(t<1$ in all four cases). Therefore, any effects reported below for yoghurt colour cannot be attributed to the taste of the yoghurts, but must instead be attributable to colour.

The results demonstrate that the colour of the spoons affected the taste of the food sampled from it. Four repeated measures ANOVAs were performed (one for
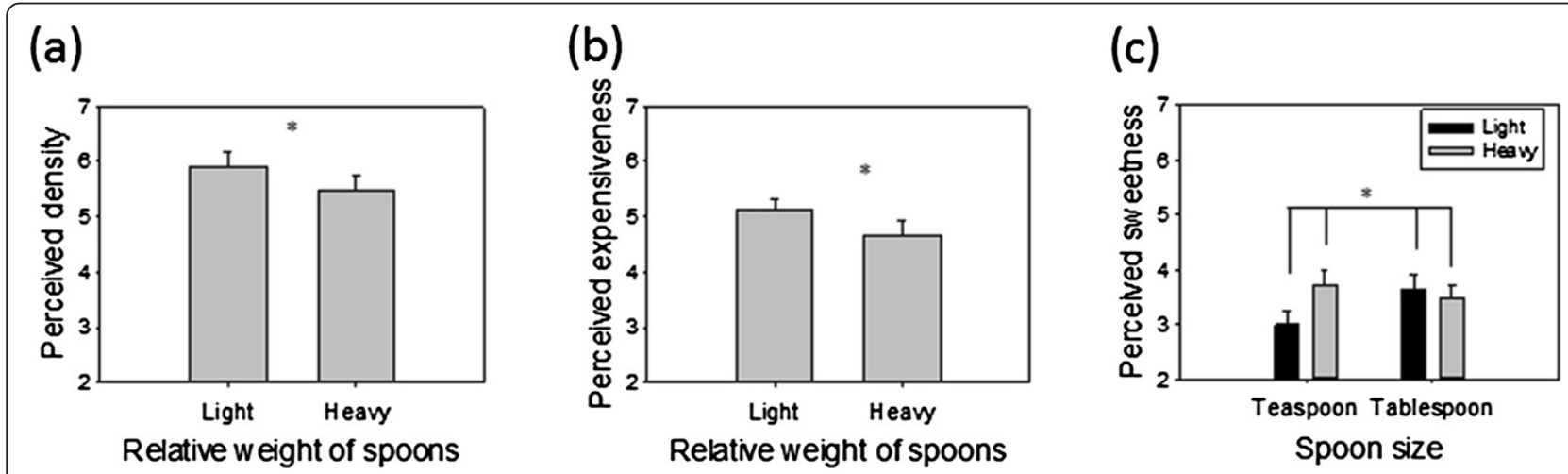

Figure 1 Experiment 1: How the weight of the spoon influenced participants' taste perception. Larger numbers on all y-axes indicate more of the measured property. Error bars represent the standard error of the mean. ${ }^{*} P<.05$; ${ }^{*} P<.01$. (a) Yoghurt sampled from light spoons is perceived as denser than the same yoghurt when sampled from a heavy spoon. (b) Yoghurt sampled from a light spoon is perceived as more expensive than the same yoghurt sampled from the heavy spoon. (c) The rated sweetness of the yoghurt varied with both spoon size and spoon weight. 
each rating: expensiveness, liking, sweetness, and saltiness) with two within-participant variables: Spoon Colour (five levels) and Yoghurt Colour (two levels). A significant interaction effect was obtained on the saltiness ratings $\left(\mathrm{F}_{4,156}=3.645, P=.007\right.$, eta $_{\mathrm{p}}^{2}=.084$, see Figure $\left.2 \mathrm{a}\right)$. None of the other main effects or interaction terms reached significance $(P<.05)$. This interaction was followed up with pairwise comparisons of the saltiness ratings for the two coloured yoghurts on each spoon colour. Tasting the yoghurt from the blue spoon resulted in participants giving significantly saltier ratings for the pink yoghurt (mean $(\mathrm{M})=4.90 \pm \mathrm{SE} 0.27$ ) than for the white yoghurt $(\mathrm{M}=4.05 \pm \mathrm{SE} 0.28)\left(\mathrm{t}_{39}=2.73, P=.009\right)$. This is similar to the effects previously reported: A blue coloured bowl also generated an illusory saltiness in unsalted popcorn in Harrar et al.'s (2011) study.

Indeed, blue packaging is often associated with salty snack products ([32], at least in the UK where the present study was conducted). This observation may help to explain the association-expectation link that may have driven the perception of saltiness when tasting from the blue spoon (see also [39]). Our post-hoc dissonance interpretation of the salty effects of a blue spoon is as follows: It might be that consumers expect saltiness when they see white food on a blue background (white yoghurt on blue cutlery). When this expectation is not met, there is a magnification of the dissonance experienced by the participant who might therefore rate the sample as that much less salty than the other samples (that would have been associated with less salty expectations).

ANOVAs were also conducted in order to test specific contrasts. As white is the most common colour for plastic spoons, we compared those responses obtained with each coloured spoon to the responses obtained when using a white spoon, using a $2 \times 2$ repeated measures ANOVA (two spoon colours and two yoghurt colours). One might also expect red to, for example, evoke an illusory perception of sweetness (based on sensation transfer [26]; see also [20,28]), or we might expect red to
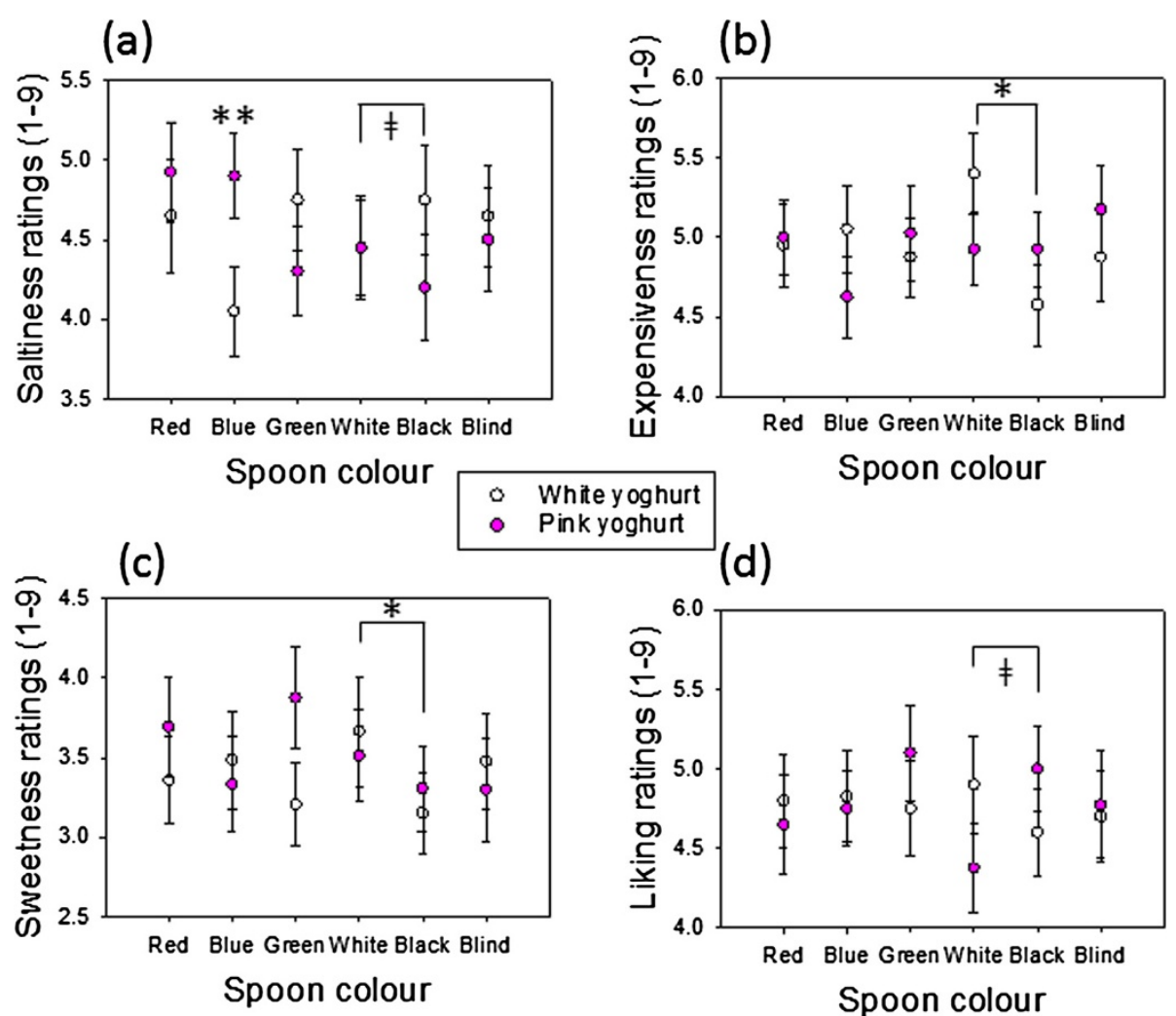

(d)

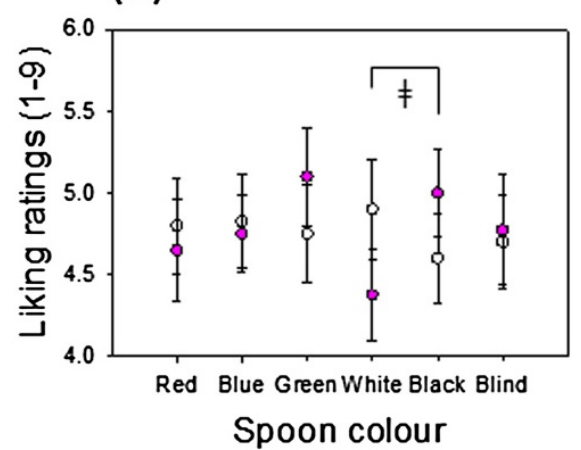

Figure 2 Experiment 2: The effect of colour on taste. Larger numbers on all y-axes indicate more of the measured property. Error bars represent the standard errors of the mean. $\neq P<.10$; ${ }^{*} P<.05$. (a) Following up on a significant interaction effect for spoon colour $x$ yoghurt colour on perceived saltiness, the two yoghurts tasted on the blue spoon were found to be rated significantly differently. Using contrast analysis, black and white spoons also had opposite effects on the perceived saltiness of white and pink yoghurt. (b) Using contrast analysis, we found an interaction effect between spoon colour (black or white) and yoghurt colour (pink or white) on the perceived expensiveness of the yoghurt. (c) Contrasting black and white spoons, we found that black spoons appear to make both yoghurts appear less sweet. (d) There was a trend towards an interaction between spoon colour and yoghurt colour when the black versus white spoon contrast was tested, which follows the same pattern as the expensiveness ratings seen in (b). 
cause a certain consumption aversion [23]. However, there were no reliable effects of colouring the food, and colouring the cutlery; there was no obvious 'whiteness' or 'redness' effect. The lack of a consistent 'red' effect when the food and the cutlery is coloured is informative in its own right.

There are three possible accounts for these inconsistencies across the studies of coloured tableware that we can think of: First, the mood elicited by colour might be different in and across the population [40]. Second, as suggested above, rather than colour itself, colour contrast (or colour combinations) might elicit a certain mood (or expectation) and thus response (see the 'additivity of colour emotion' in [41]). Third, as suggested in the discussion of Experiment 1, the effects might be mediated by expectations [20].

We also compared the responses that were obtained when the participants sampled from black versus white spoons which yielded significant or borderline-significant effects, in all four ratings ${ }^{\mathrm{b}}$. With regard to the perceived sweetness, there was a significant main effect of spoon colour $\left(\mathrm{F}_{1,39}=5.17, P=.028\right.$, eta $\left.{ }_{\mathrm{p}}^{2}=.117\right)$, with the black spoons appearing to make both yoghurts appear less sweet than when tasted from white spoons (see Figure 2c). This confirms Piqueras-Fiszman's [21] previous reports that strawberry mousse is perceived as sweeter when sampled from a white plate rather than a black one.

Piqueras-Fiszman, Alcaide, et al. [21] also reported greater liking for the mousse presented on the white plate. Here, however, we report an interaction between food colour and tableware colour. We found a trend towards a significant interaction of spoon colour and yoghurt colour on participants' overall liking of the yoghurt $\left(\mathrm{F}_{1,39}=3.917, P=.055\right.$, eta $\left.\mathrm{p}_{\mathrm{p}}^{2} .091\right)$. In comparison to the black spoon, the white spoon made the white yoghurt appear more pleasant while the pink coloured yoghurt was rated as less pleasant (see Figure 2d).

Piqueras-Fiszman, Alcaide, et al. [21] did not observe any effect of plate-colour on perceived quality. Their result can be compared with the present results concerning perceived expensiveness. There was a significant interaction between spoon colour and yoghurt colour on the perceived expensiveness of the yoghurt $\left(\mathrm{F}_{1,38}=4.957, P=.032\right.$, eta $\left.\mathrm{p}_{\mathrm{p}}^{2}=.115\right)$. The pink yoghurt was rated as equally expensive when tasted from both spoons (same result as Piqueras-Fiszman et al. for a pink mousse) while the white yoghurt was rated as tasting more expensive when sampled from the white spoon than when tasted from the black spoon (see Figure $2 \mathrm{~b}$ ). The interaction between cutlery colour and food colour on expensiveness, overall liking, and sweetness perception contrasts with previous reports, which have been limited in only testing one food colour. The present results therefore represent an important extension of the results of Piqueras-Fiszman, Alcaide, et al.'s recent study [21].

There was also a marginally significant interaction effect for perceived saltiness $\left(\mathrm{F}_{1,38}=3.11, P=.086\right.$, eta $\left.\mathrm{p}_{\mathrm{p}}^{2}=.076\right)$; white spoons provide a fairly consistent perception of saltiness, whereas the black spoon trended toward making the white yoghurt saltier $(\mathrm{M}=4.75 \pm \mathrm{SE} 0.32)$ as compared to the pink-coloured yoghurt sampled from the same black spoon $\left(\mathrm{M}=4.20 \pm \mathrm{SE} 0.32 ; \mathrm{t}_{39}=1.92\right.$, $P=.062$ ). There are no previous reports of saltiness perception for food sampled from black versus white tableware so we are unable to compare these results to any previous findings.

Only the perceived sweetness ratings were perfectly consistent with the previous literature, because there was no interaction effect between the colour of the plateware and the colour of the cutlery. However, it is important to note that the current and previous food samples tested certainly do not cover the full range of possibilities. It will therefore be important for future research investigating the effect of colour on taste/flavour, to consider both the cutlery and the plateware - as well as the likely effects of any ambient colour [12-14].

\section{Experiment 3}

In our third and final experiment, we investigated the effect of the shape of the cutlery on people's taste perception. Mixed model repeated measures ANOVAs were performed for each rating (expensiveness, liking, saltiness, sweetness, and sharpness) with two withinparticipant variables: Cutlery (four levels) and Cheese (two levels) and one between-participant variable (Experience with cheese, see Ratings in Methods for a description). We report that taste perception is mediated by experience, and that the cutlery used has surprising effects on the taste of the food. Those who had heard of the term 'sharp' being applied to cheese preferred the sharper cheese (that is, gave it a higher liking rating than those who had not heard of the term). They also exhibited a rather different reaction to the young cheese (liking it less, valuing it less, and perceiving it as less sweet than the naïve cheese tasters).

\section{Expensiveness}

There was a significant main effect of Cheese $\left(\mathrm{F}_{1,28}=\right.$ 25.627, $P<.001$, eta $\left.a_{\mathrm{p}}^{2}=.48\right)$, and a more informative interaction between Cheese and Experience $\left(\mathrm{F}_{1,28}=5.77\right.$, $P=.023$, eta $\mathrm{p}_{\mathrm{p}}^{2}=.17$, see Figure $3 \mathrm{a}$ ). Tasters with more cheese-tasting experience identified the young cheese as less expensive than the more naïve tasters $\left(t_{28}=2.738\right.$, $P=.011$ ), but the two groups responded similarly for the aged cheese. The young cheese used in the present study was indeed less expensive than the aged cheese ( $£ 5.40 / \mathrm{kg}$ versus $£ 7.49 / \mathrm{kg}$ ), as is normally the case, since 

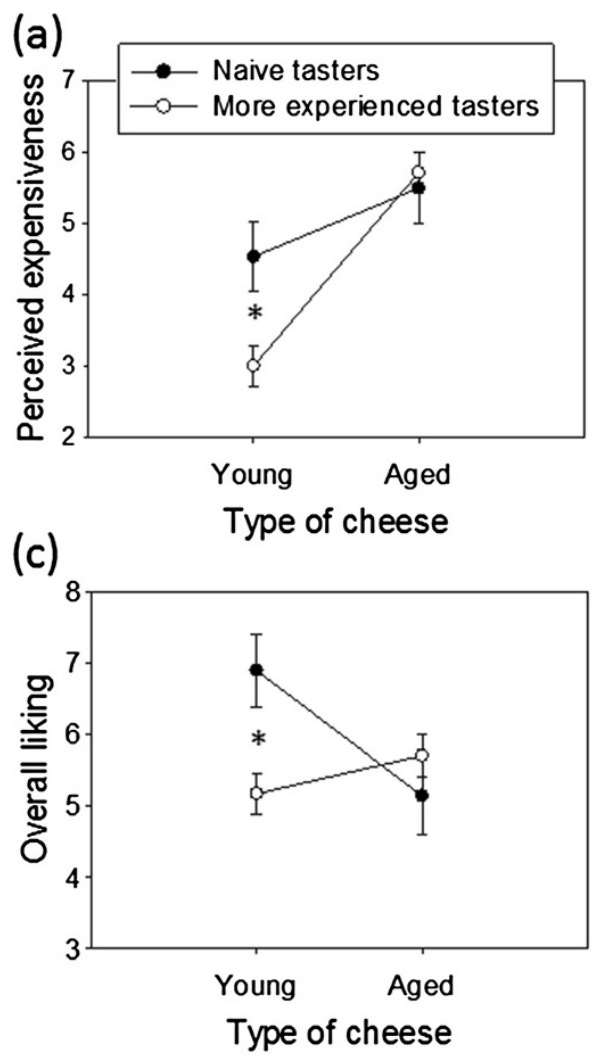

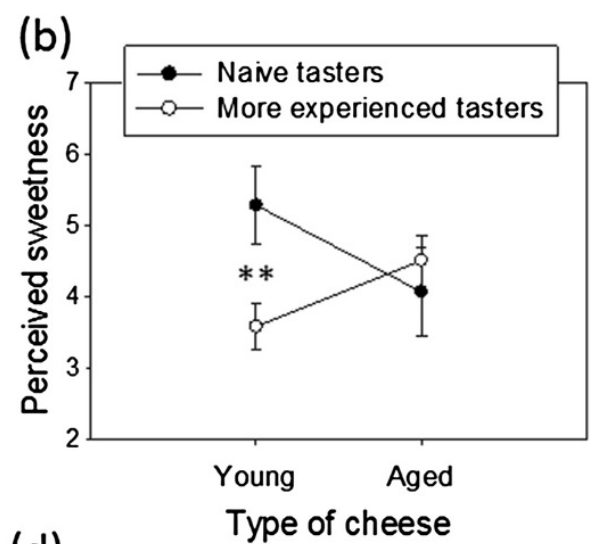

(d)

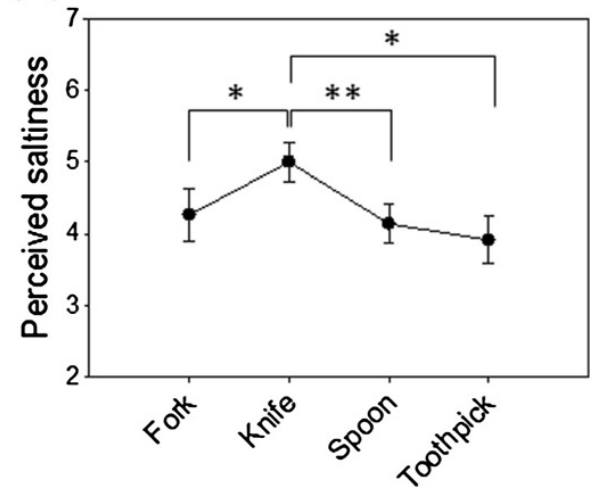

Figure 3 Experiment 3: The effect of the shape of the cutlery on taste for young and aged cheese. Larger values on all $y$-axes indicate more of the measured property. Error bars represent the standard errors of the mean ${ }^{*} P<.05$; ${ }^{* *} P<.01$. (a) The significant interaction effect between Cheese type and Experience with cheese reveals that those tasters with more experience with cheese correctly valued the young cheese as less expensive than the aged cheese, which the naive tasters did not do. (b-c) The interaction was also significant for perceived sweetness/liking, which when followed up indicated that naive tasters rated the young cheese as sweeter/more liked, while those with more experience of cheese rated the aged cheese as sweeter/more liked. (d) There was a trend towards a main effect of cutlery shape affecting the perceived saltiness of the cheese. This was followed up with pairwise comparisons and revealed that the cheese samples were rated as significantly more salty when sampled from a knife as compared to the other cutlery tested.

the process of aging incurs additional costs and is reflected in the final price.

\section{Sweetness}

There was a significant interaction between Cheese and Experience $\left(\mathrm{F}_{1,28}=8.229, P=.008\right.$, eta ${ }_{\mathrm{p}}^{2}=.227$, see Figure $3 \mathrm{~b})$. The more experienced tasters identified the young cheese as less sweet than the more naïve tasters $\left(\mathrm{t}_{28}=2.76, P=.010\right)$.

\section{Overall liking}

There was a significant interaction between Cheese and Experience $\left(\mathrm{F}_{1,28}=4.911, P=.035\right.$, eta ${ }_{\mathrm{p}}^{2}=.149$, see Figure 3c): those who had less experience with cheese enjoyed the young cheese more than the more experienced tasters $\left(t_{28}=2.907, P=.007\right)$. Since these effects are significant only in the context of the familiarity of the participants with cheese, we suggest that experience related expectations likely account for these effects.

\section{Sharpness}

The aged cheese was perceived as sharper than the young cheese (main effect of Cheese, $F_{1,28}=150.12$, $P<.001$, eta $\left.\mathrm{p}_{\mathrm{p}}^{2}=.843\right)^{\mathrm{c}}$. Other than this obvious effect, there was no variation in perceived sharpness based on the different cutlery or the prior experience of the participants with cheese. Although the shape, or sharpness, of the cutlery did not affect the perceived 'sharpness' of the cheese, the shape of the cutlery did affect the perceived saltiness.

\section{Saltiness}

There was a significant main effect of Cheese $\left(\mathrm{F}_{1,28}=\right.$ 22.739, $P<.001$, eta ${ }_{\mathrm{p}}^{2}=.448$ ). The aged cheese was correctly perceived as being saltier - which it was (aged: $1.8 \mathrm{~g}$ salt equivalent $/ 100 \mathrm{~g}$; young: $1.6 \mathrm{~g}$ salt equivalent/ $100 \mathrm{~g})$. There was also a significant main effect of Cutlery $\left(\mathrm{F}_{3,84}=3.229, P=.026\right.$, eta ${ }_{\mathrm{p}}^{2}=.103$, see Figure $\left.3 \mathrm{~d}\right)$ : The participants identified the cheese as saltier when 
sampled from a knife $(\mathrm{M}=5.00, \mathrm{SE}=0.28)$ as compared to the spoon $(\mathrm{M}=4.14, \mathrm{SE}=0.27, P=.004)$, the toothpick $(\mathrm{M}=3.91, \mathrm{SE}=0.33, P=.020)$, or the fork $(\mathrm{M}=4.27$, $\mathrm{SE}=0.37, P=.032)$.

Knives are not usually inserted into one's mouth, but during this experiment the participants were explicitly instructed to put each of the items of cutlery into their mouths to keep circumstances consistent. This unusual behaviour might perhaps have caused the increase in perceived saltiness. Alternatively, experience may play a role. In cheese shops, samples are often given directly from the knife. Cheese shops often sell more aged, therefore saltier cheeses. Eating cheese from the knife may therefore have brought out additional perceived saltiness. Cheese samples given out at cheese shops or food stores are one of the few times where extrapolating from single sample laboratory conditions seem to mimic real life.

Laboratory-based studies, such as those presented here, that have assessed taste perception (rather than total food or beverage intake) are often based on a single food sample. It is normally difficult to generalise these results to restaurant or home settings in order to assess what effects tableware might have over the course of an entire meal [9]. There are, however, settings to which the results of data collected with a single sample experiment model might generalize. When it comes to purchasing food, we often do so after being given a single free sample. One might therefore want to conclude, based on the results obtained here, that for those who like salty aged cheeses, they might be more likely to buy a cheese they have just sampled from a knife (as in a fancy cheese shop) rather than from a spoon, fork, or toothpick. It remains to be seen how cheese might taste after the more realistic situation of peeling a sample of cheese off a knife (pointed at the consumer) held out by the cheese monger standing behind the counter.

The fact that the toothpick was made of wood (and was lighter than the other utensils) was considered since Experiment 1 had revealed that the weight of the cutlery can affect the taste (see also [36]). However, we did not find any ratings with toothpick samples to stand out from the other cutlery that was tested, and there is therefore no need to further interpret the toothpick results.

\section{Conclusions}

The results of the three experiments reported in the present study extend the findings of recent research that has demonstrated that the properties of the tableware can affect people's perception of food samples [3]. The results reported here extend these previous findings by demonstrating that the absolute weight (context free) does not seem to be the perceptual quality that is transferred from bowl, or cutlery, to food. Rather, it would appear to be the expected weight of the tableware, a relative attribute that depends on the cutlery's appearance, the physical materials, the type of food being consumed, and potentially individual differences in tactile preferences ([42]; for a review see [43]), that might most appropriately explain the effects on taste.

One area for future research would be to look at how the effects of taste perception reported here and elsewhere can be used to predict how much people eat (or how much salt people add to their meal, say, if they are eating with a 'salty' blue knife from a 'salty' blue bowl)? There is already some evidence to suggest that the portion size [44] and the size of the spoon/bowl ([8-10]; though see [6]) can affect how much people eventually consume.

Can red, or other specific colours, promote consumption or else perhaps discourage it? In addition to the small effects of colour reported here, Genschow et al. [23] demonstrated that people consume less when a snack is presented on a red plate, or a drink has a red label (see similar food avoidance in monkeys in [45]). Here, we would like to suggest that red could, for example, be used to serve food to people who need to reduce their food intake, but should certainly not be used for those who are underweight. Presently, in the United Kingdom, hospital patients who have been identified as malnourished are put on 'The red tray system' in order to allow hospital staff to easily identify and help the patients who need support with eating [46]. However, given the aforementioned results, red appears to be the worst possible tray colour (psychologically speaking) to serve food on for those individuals who are being encouraged to eat more. Certainly more research is needed, preferable in whole meal settings rather than single sample experiments, in order to determine which tray colour, and tableware attributes in general, might encourage or discourage consumption before considering clinical applications.

Marteau et al. [2] have recently suggested that product design, or, more generally, environmental changes, constitute a promising avenue for improving people's consumption behaviours. Environmental changes force people to break routine, which therefore generates the possibility of making changes to their consumption behaviours. Indeed, many of the effects reported here might be related more to the novelty of the stimuli (a plastic spoon weighing 11 grams) that makes people stop and think and taste 'properly', rather than the spoon actually producing illusory taste sensations (see also [13]). Similarly, Marteau et al.'s suggestion of laying out a grocery store in such a way that maximises healthful purchasing might, then, only work as long as the layout remains novel for the shopper. 
What might be particularly effective in terms of reducing people's unhealthy eating habits would be to make unhealthy food difficult to find (not grouped together with like products) and to have unintuitive packaging so that blue no longer signals a salty snack. Keeping people on their toes, and unable to fulfil expectations, might make them slow down their consumption so that they might eat less or make better food choices in the market.

\section{Methods}

\section{Participants}

Thirty-five participants with normal colour vision took part in the Experiment 1 (22 female; median age of 26 years). Forty naïve Oxford University undergraduate students participated in Experiment 2 (28 female; median age 19 years). Thirty naïve Oxford University undergraduate students, participated in Experiment 3 (17 female; median age 18 years; all of the participants were British, that is, native English speakers, save one participant who was bilingual). The studies were approved by the Central University Research Ethics Committee of the University of Oxford. All of the participants gave their informed consent prior to taking part in the study. Each experiment lasted for less than 10 minutes.

\section{Materials}

\section{Experiment 1}

Five plastic spoons were used: two simple small plastic teaspoons, two simple large plastic tablespoons, and one fancy plastic spoon (see Figure 4a). For the simple spoons, one of each spoon size was artificially weighted
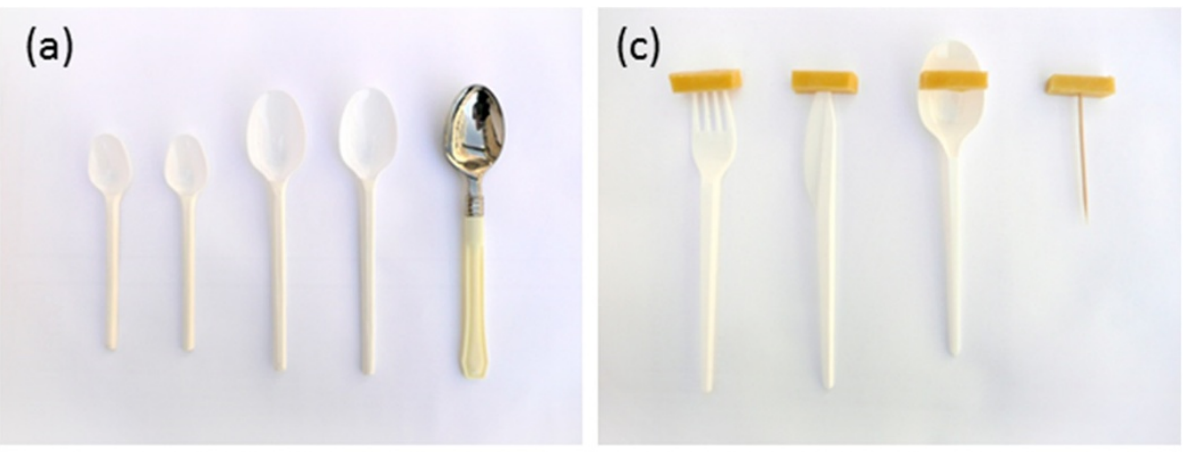

(b)

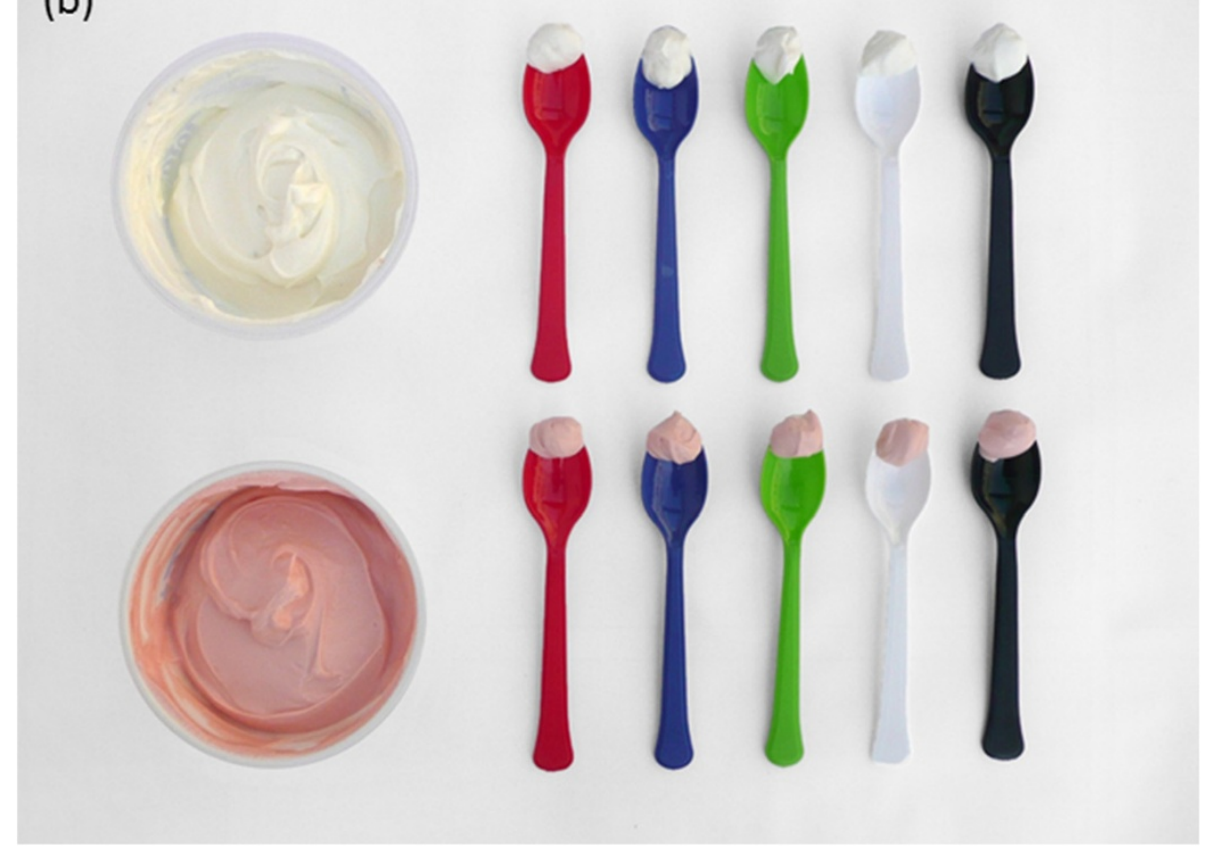

Figure 4 Materials. a) The five spoons from which the participants sampled the yoghurt in Experiment 1. From the left, the second and fourth spoons had weights hidden in the handles. b) The five coloured spoons and the yoghurt (one white, and one artificially coloured with red food dye) used in Experiment 2. c) The cutlery and cheese used in Experiment 3 is shown as it was presented to participants (though participants would have only seen one piece of cutlery at a time). 
with lead wire embedded in the handle and then covered with white heat shrink tubing. The unweighted spoon handles were also covered with the same white heat shrink tubing so that the 'heavy' and 'light' spoons were visually identical. The teaspoons weighed $2.35 \mathrm{~g}$ and $6.57 \mathrm{~g}$, and the tablespoons weighed $3.37 \mathrm{~g}$ and $10.84 \mathrm{~g}$. The fancy spoon's ornate handle did not allow for weights to be embedded, and could obviously not be covered - thus, there was only a 'light' version of this spoon (although it may have looked heavy). It weighed $7.30 \mathrm{~g}$ and was used to compare the effects of tasting food from simple versus more expensive and elaborate plastic cutlery. The participants sampled Total FAGE ${ }^{\mathrm{m}}$ Greek yoghurt five times.

\section{Experiment 2}

Plastic spoons in five different colours were used (see Figure 4b): red (PANTONE $186 \mathrm{C}$ ), blue (PANTONE $7686 \mathrm{C}$ ), green (PANTONE $368 \mathrm{C}$ ), black (PANTONE Black $6 \mathrm{C}$ ), and white. The participants once again sampled yoghurt (Total FAGE ${ }^{\mathrm{im}}$ Greek Yoghurt) from each spoon colour twice, once with the yoghurt in the usual 'white' colour, and the other time it was artificially dyed with red food colouring. Twenty drops of Dr. Oetker ${ }^{\mathrm{rm}}$ Natural Red Food Colour mixed into a $150 \mathrm{ml}$ pot of yoghurt made the two samples significantly different in colour (see Figure 4b).

\section{Experiment 3}

Four items were used to serve the participant a sample of cheese; a white plastic fork, a knife, a spoon, and a wooden toothpick (see Figure 4c). The participants sampled one of two types of cheese (Tesco Everyday Value Mild Cheddar, and Tesco Everyday Value Extra Mature Cheddar) cut into small rectangles (see Figure 4c). The participants were asked not to remove the cheese from the utensil, but instead to insert the utensil into their mouth directly ${ }^{\mathrm{d}}$.

\section{Ratings}

The participants rated the taste of each food sample on anchored 9-point Likert scales as follows.

\section{Experiment 1}

Perceived density of the yoghurt (1-Very thin to 9-Very thick); Perceived expense/value (1-Very inexpensive to 9-Very expensive); Perceived sweetness (1-Not at all sweet to 9-Very sweet); and how much they liked it (1-Extremely dislike to 9-Extremely like).

\section{Experiment 2}

Perceived expense, sweetness, and overall liking of yoghurt as in Experiment 1. In addition, there was a perceived saltiness scale (1-Not at all salty, to 9-Extremely salty). While yoghurt is not normally described as salty, participants were asked to rate the sample on this scale so that results could be compared across with previous results (for example, [20]); Does blue always signify saltiness, or only for popcorn?

\section{Experiment 3}

Perceived value, perceived sweetness, perceived saltiness, and the overall liking of the cheese had same anchors as reported in Experiments 1 and 2. An additional sharpness scale was also shown to participants (1-Not at all sharp to 9-Extremely sharp). After sampling all of the cheeses and completing the ratings, the participants were given one final question 'Have you ever heard the term 'sharp' when describing cheese (yes or no)?' The participants were divided based on their response to this final question for further analysis based on the assumption that the response demonstrated a certain familiarity with cheese. The one participant who was bilingual but not British (she had grown up in France but had one English parent) responded 'Yes' to this final question indicating a certain knowledge of cheese, and of English words used to describe cheese.

\section{Procedure}

The participants stood in front of a computer, which informed them that they would be presented with food prototypes, and that, as such, the differences between the samples would sometimes only be subtle. The participants were also told that some samples might be repeated. After this, participants were presented with a random 3-digit code (the codes were generated using an online random digit generator) that corresponded to a given sample that the participants should taste next (order randomised between participants). The experimenter selected the appropriate sample (cutlery and food) from behind an opaque shield and then handed it to the participant. While the participant tasted the food, the rating questions appeared sequentially on the screen (see Ratings for details) in a randomised order. The participants had to respond by typing in the number on a keyboard with no time limit. No place was provided for the participants to set the cutlery down, thus encouraging them to hold onto it until they had finished rating the sample. Approximately one quarter of the participants tried to hand the cutlery back to the experimenter before entering their ratings. They were casually but explicitly instructed to hold onto it until they had finished responding. After rating the sample on all of the scales, the next 3-digit code would appear and the participants were instructed to take at least a bite of a plain cracker (a Jacob's cream cracker) and a sip of water in order to cleanse their palate. Meanwhile, the experimenter prepared the next sample. 
At the end of the experiment many participants volunteered the information about how many samples they perceived. Only about 5\% guessed correctly, while the rest perceived at least 2 to 4 different samples.

\section{Experiment 1}

After each response, a simple algebraic question (addition or subtraction of two digits below 10) appeared on the screen and the participant had to make a speeded response on the keyboard ${ }^{\mathrm{e}}$.

\section{Experiment 2}

Two 3-digit codes corresponded to blind tasting conditions were included in the design in order to ensure that the two yoghurts (one coloured and one white) actually tasted the same. For the blind tasting condition, the participants wore a blindfold when they were handed the spoon from which they sampled the yoghurt. Participants then handed the spoon back to the experimenter (while still blindfolded) and it was only after the cutlery item was safely hidden behind the screen that they could remove the blindfold and rate the sample.

\section{Experiment 3}

No differences to general description above.

\section{Endnotes}

${ }^{\text {a }}$ The theory that these taste effects are driven by expectation (in this case, expecting the cutlery to have a certain weight) leads to a number of further predictions. The expectations-based account ought to predict that the first exposure to the odd cutlery would produce a significantly heightened response. Whereas, as the experiment went on, the participants would have less expectations (having been fooled already) so might express less discontent with the yoghurt sampled from a surprisingly weighted spoon. To test this hypothesis, we examined the responses to the three oddly weighted spoons (weighing $6.57 \mathrm{~g}, 7.30 \mathrm{~g}$, and $10.84 \mathrm{~g}$ ) in the order in which they were presented (randomly across participants). We found a significant linear decreasing effect for density ratings $\left(\mathrm{F}_{1,34}=6.54, P=.015\right)$; marginally significant linear increasing effects for expensiveness ratings $\left(\mathrm{F}_{1,34}=3.236, P=.081\right)$; and a significant linear increasing effect for sweetness $\left(F_{1,34}=20.50, P<.001\right)$. For sweetness ratings, the first odd spoon made the yoghurt appear least sweet $(\mathrm{M}=2.88 \pm \mathrm{SE}=0.18)$, the second odd spoon made the yoghurt appear slightly more sweet $(M=3.40 \pm S E=0.27)$, and the third spoon made the yoghurt appear the sweetest $(M=4.08 \pm S E=0.28)$, regardless of which odd spoon was presented at which time; this direction of effect for sweetness was observed for 31 out of the 35 participants tested in Experiment 1 .
${ }^{\text {b}}$ We also compared coloured versus white spoons for both yoghurt samples (the 'coloured spoons' data was calculated by taking the mean of responses from the red, blue, and green spoons). This contrast analysis did not reveal any significant effects for any of the four ratings.

${ }^{\mathrm{C}}$ The same pattern of results was obtained if only the 'experienced' group's data was analysed (that is, only those participants that reported knowing what the word meant, $\left.\mathrm{F}_{1,22}=157.20, P<.001\right)$.

${ }^{d}$ This was done under the pretence of not altering the cheese sample by touching it, a logic that was not contested by any of the participants. This helped to ensure that the method of eating remained fairly constant, rather than having people eat the cheese with their hand in the 'knife' situation but from the utensil directly in the other conditions. This also meant that an oral-tactile sensation was available in each condition as they put the tool in their mouth.

${ }^{\text {e}}$ Pilot testing suggested that participants may have been trying to remember their responses from previous trials/samples and were reporting the same response rather than actually reporting their perception of the yoghurt at the time. This algebraic distraction task was therefore designed to make it more difficult for participants to remember their response to the preceding trial, which was confirmed during debriefing. The algebraic responses were not analysed. Preliminary testing for Experiment 2 and 3 revealed that participants were not matching responses across samples, potentially because there were two clearly different food samples used in these studies. An algebraic distraction task, as used in Experiment 1, was therefore not necessary in Experiment 2 or 3 .

\section{Competing interests}

The authors declare that they have no competing interests.

\section{Authors' contributions}

$\mathrm{VH}$ designed the study, prepared the stimuli, collected the data (or supervised undergraduate students to collect the data), performed the statistical analysis, and drafted and revised the manuscript. CS participated in the conception of the studies, and helped to draft and revise the manuscript. Both authors read and approved the final manuscript.

\section{Authors' information}

$\mathrm{VH}$ has a PhD in Psychology from York University (Toronto, Canada) and is currently a post-doc in CS's lab in the Department of Experimental Psychology at Oxford University (Oxford, UK). CS has a PhD in Experimental Psychology from the University of Cambridge and has been a University Lecturer at Oxford University since 1997.

\section{Acknowledgements}

We would like to thank Rose Qian for helping to set up Experiment 1 and Timothy Hogwood-Wilson for collecting the data for Experiments 2 and 3. We would also like to thank Elizabeth Willing for photographing the stimuli and for design suggestions. Vanessa Harrar holds a Mary Somerville Junior Research Fellowship from Somerville College, Oxford University, UK.

Received: 11 April 2013 Accepted: 3 June 2013

Published: 26 June 2013 
References

1. Neal DT, Wood W, Quinn JM: Habits: a repeat performance. Curr Dir Psychol Sci 2006, 15:198-202

2. Marteau TM, Hollands GJ, Fletcher PC: Changing human behaviour to prevent disease: the importance of targeting automatic processes. science 2012, 337:1492-1495.

3. Spence C, Harrar V, Piqueras-Fiszman B: Assessing the impact of the tableware and other contextual variables on multisensory flavour perception. Flavour 2012, 1:1-12.

4. Wansink B, van Ittersum K: Bottoms up! The influence of elongation on pouring and consumption. J Consum Res 2003, 30:455-463.

5. Wansink B, van Ittersum K: Shape of glass and amount of alcohol poured comparative study of the effect of practice and concentration. Br Med J 2005, 331:1512-1514

6. Rolls BJ, Roe LS, Halverson KH, Meengs JS: Using a smaller plate did not reduce energy intake at meals. Appetite 2007, 49:652-660.

7. Van Ittersum K, Wansink B: Plate size and color suggestibility: the delboeuf Illusion's bias on serving and eating behavior. J Consum Res 2012, 39:215-228.

8. Wansink B, Cheney MM: Super bowls: serving bowl size and food consumption. J Am Med Assoc 2005, 293:1727-1728.

9. Mishra A, Mishra $H$, Masters $T$ : The influence of the bite size on quantity of food consumed: a field study. J Consum Res 2011, 38:791-795.

10. Wansink B, van Ittersum K, Painter JE: Ice cream illusions: Bowl size, spoon size, and self-served portion sizes. Am J Prev Med 2006, 31:240-243.

11. Spence C: Auditory contributions to flavour perception and feeding behaviour. Physiology \& Behaviour 2012, 107:505-515.

12. Oberfeld $D$, Hecht $H$, Allendorf $U$, Wickelmaier F: Ambient lighting modifies the flavor of wine. J Sens Stud 2009, 24:797-832.

13. Wansink B, van Ittersum K: Fast food restaurant lighting and music can reduce calorie intake and increase satisfaction. Psychological Reports: Human Resources \& Marketing 2012, 111:1-5.

14. Wilson GD, Gregson RAM: Effects of illumination on perceived intensity of acid tastes. Aust J Psychol 1967, 19:69-72

15. Brenner $E$, Smeets JBJ: Size illusions influence how we lift but not how we grasp an object. Exp Brain Res 1996, 111:473-476.

16. Auvray $M$, Spence $C$ : The multisensory perception of flavor. Conscious Cogn 2008, 17:1016-1031.

17. Guéguen N: The effect of glass colour on the evaluation of a beverage's thirst-quenching quality. Curr Psychol Lett 2003, 11(2):1-6.

18. Favre JP, November A: Color and communication. Zurich: ABC-Verlag; 1979.

19. Piqueras-Fiszman B, Spence $C$ : The influence of the color of the cup on consumers' perception of a hot beverage. J Sens Stud 2012, 27:324-331.

20. Harrar V, Piqueras-Fiszman B, Spence C: There's no taste in a white bowl. Perception 2011, 40:880-892.

21. Piqueras-Fiszman B, Alcaide J, Roura E, Spence C: Is it the plate or is it the food? assessing the influence of the color (black or white) and shape of the plate on the perception of the food placed on it. Food Quality \& Preference 2012, 24:205-208.

22. Desmet $P$, Schifferstein HN: Sources of positive and negative emotions in food experience. Appetite 2008, 50:290-301.

23. Genschow $O$, Reutner $L$, Wanke $M$ : The color red reduces snack food and soft drink intake. Appetite 2012, 58:699-702

24. Pelchat ML, Johnson A, Chan R, Valdez J, Ragland JD: Images of desire: food-craving activation during fMRI. Neurolmage 2004, 23:1486-1493.

25. Small DM, Zatorre RJ, Dagher A, Evans AC, Jones-Gotman M: Changes in brain activity related to eating chocolate from pleasure to aversion. Brain 2001, 124:1720-1733.

26. Maga JA: Influence of color on taste thresholds. Chemical Senses and Flavour 1974, 1:115-119.

27. Johnson J, Clydesdale FM: Perceived sweetness and redness in colored sucrose solutions. J Food Sci 1982, 47:747-752

28. Spence C, Levitan C, Shankar MU, Zampini M: Does food color influence taste and flavor perception in humans? Chemosens Percept 2010, 3:68-84.

29. Deliza R, MacFie HJH: The generation of sensory expectation by external cues and its effect on sensory perception and hedonic ratings: A review. J Sens Stud 1996, 11:103-128.

30. Schaefer HM, Schmidt V: Detectability and content as opposing signal characteristics in fruits. Proc Roy Soc Lond B 2004, 271(Suppl):S370-S373.

31. Cheskin L: How to predict what people will buy. New York: Liveright; 1957.
32. Piqueras-Fiszman B, Spence C: Crossmodal correspondences in product packaging: Assessing color-flavor correspondences for potato chips (crisps). Appetite 2011, 57:753-757.

33. Piqueras-Fiszman B, Spence C: Do the material properties of cutlery affect the perception of the food you eat? An exploratory study. J Sens Stud 2011, 26:358-362.

34. Piqueras-Fiszman $B$, Spence $C$ : The weight of the container influences expected satiety, perceived density, and subsequent expected fullness. Appetite 2012, 58:559-562.

35. Piqueras-Fiszman B, Harrar V, Roura E, Spence C: Does the weight of the dish influence our perception of food? Food Quality \& Preference 2011, 22:753-756.

36. Piqueras-Fiszman B, Laughlin Z, Miodownik M, Spence C: Tasting spoons: Assessing how the material of a spoon affects the taste of the food. Food Quality and Preference 2012, 24:24-29.

37. Gal D, Wheeler SC, Shiv B: Cross-modal influences on gustatory perception. 2007, Available at SSRN: http://ssrn.com/abstract=1030197.

38. Piqueras-Fiszman B, Spence C: The weight of the bottle as a possible extrinsic cue with which to estimate the price (and quality) of the wine? Observed correlations. Food Quality \& Preference 2012, 25:41-45.

39. Lyman B: A psychology of food, more than a matter of taste. New York: Avi, van Nostrand Reinhold: 1989.

40. Madden TJ, Hewett $K$, Roth MS: Managing images in different cultures: a cross-national study of color meanings and preferences. J Int Mark 2000 8:90-107

41. Ou LC, Luo MR, Woodcock A, Wright A: A study of colour emotion and colour preference. part II: Colour emotions for two-colour combinations. Color Res Appl 2004, 29:292-298.

42. Krishna A, Morrin M: Does touch affect taste? the perceptual transfer of product container haptic cues. J Consum Res 2008, 34:807-818.

43. Gallace A, Spence C: In touch with the future: From cognitive neuroscience to virtual reality. Oxford: Oxford University Press; 2013. in Press.

44. Rolls BJ, Roe LS, Meengs JS, Wall DE: Increase the portion size of sandwich increases energy intake. J Am Diet Assoc 2004, 104:367-372.

45. Khan SA, Levine WJ, Dobson SD, Kralik JD: Red signals dominance in male rhesus macaques. Psychol Sci 2011, 22:1001-1003.

46. Breadley $L$, Rees C: Reducing nutritional risk in hospital: the red tray. Nurs Stand 2003, 17:33-37.

\section{doi:10.1186/2044-7248-2-21}

Cite this article as: Harrar and Spence: The taste of cutlery: how the taste of food is affected by the weight, size, shape, and colour of the cutlery used to eat it. Flavour 2013 2:21.

\section{Submit your next manuscript to BioMed Central and take full advantage of:}

- Convenient online submission

- Thorough peer review

- No space constraints or color figure charges

- Immediate publication on acceptance

- Inclusion in PubMed, CAS, Scopus and Google Scholar

- Research which is freely available for redistribution 